\title{
Effect of Quebracho Bark on the Properties of Opaque Glazes
}

\author{
Kemal Köseoğlu ${ }^{1}$, Hakan Cengizler ${ }^{2 *}$, Lina İsrael İsrail ${ }^{1}$ \\ ${ }^{1}$ Ege Vocational School, Ege University, 35040, İzmir, Turkey \\ kemal.koseoglu@ege.edu.tr \\ ${ }^{2}$ Turgutlu Vocational School, Manisa Celal Bayar University, 45410 Turgutlu, Manisa, Turkey \\ *hakan.cengizler@cbu.edu.tr
}

Received: 13 May 2017

Accepted: 18 June 2018

DOI: $10.18466 /$ cbayarfbe. 312167

\begin{abstract}
In this work, the effect of quebracho bark (QB) on the physical and chemical properties of opaque glaze/glazes (OG) was investigated. Various ratios (0.25-10 weight percent) of quebracho bark were incorporated into the glazes to obtain experimental glaze recipes and melting temperatures of the glaze compositions were calculated through the fluxing factors of the oxides present in the glazes. Thereafter, the glaze compositions were fired at the calculated temperature value of $1100^{\circ} \mathrm{C}$. Viscosity, thixotropy and $\mathrm{pH}$ tests were conducted on OG and OG+QB glaze suspensions. Standard coloring analyses, crazing resistance, impact resistance, resistance to acid and alkalis, water absorption, firing strength, and surface hardness tests were conducted. After establishing the Seger formulas, surface tensions of the glazes were calculated by making use of the molar surface tension factors of the oxides already present in the glaze compositions at the same sintering temperature of $1100^{\circ} \mathrm{C}$. QB additions decreased the viscosity and standard thixotropy values of the $\mathrm{OG}$ and had no significant effect on the $\mathrm{pH}$ of the OG slurry. On the other hand, QB additions caused an increase in the whiteness (opacity) of the OG. No crazing and impact fractures were observed on the glaze surfaces. Furthermore, the glaze surfaces showed good resistance to acid and alkalis. On QB incorporation, water absorption decreased in all the experimental glazes. Firing strength and surface hardness increased with increasing QB content. According to the experimental results, 5 weight percent (wt. \%) QB addition was found to be the optimum amount.
\end{abstract}

Keywords: Opaque glaze, quebracho, viscosity, additive, thixotropy, physical properties.

\section{Introduction}

Glazes are simply glass coatings on the surface of a ceramic body, either clear transparent or in various colours. They may also be glossy or matte, translucent or opaque, smooth or even textured. The effects are limitless depending on formulation, application and combinations [1]. If a glaze, when exposed to light, refracts light beams, it is called an OG $[2,3]$. The opaqueness of a glaze arises from the existence of tiny particles of substances which are insoluble in vitreous phase and have different refraction indexes, or from trapped air bubbles held in suspension within the glaze $[2,3]$. A surer way to achieve opacity is to add an opacifying agent or opacifier into a starting batch of either frit or glaze itself [4,5]. OG cover undesired substrate colours, overcome surface defects of a ceramic body, and also supply pleasant and satisfactory esthetical appearances, besides giving sufficient mechanical properties. The most commonly used opacifiers are zirconia $\left(\mathrm{ZrSiO}_{4}\right), \mathrm{ZnO}, \mathrm{TiO}_{2}$ and $\mathrm{SnO}_{2}$ which contribute to high manufacturing costs [4]. Among the many parts of plants that are used, bark products have always played exceptionally noteworthy roles. Traditionally bark products have been particularly prominent as sources of medicine [6]. Bark has also been used as a natural dye for textile industry [7], as a low cost adsorbent [8], and in leather industry [6]. In this work, the effect of QB, as an alternative material, on the physical and chemical properties of OG was investigated. The details of the study were presented in the following paragraphs.

\section{Materials and Methods}

2.1. Material and preparation of glazed tile samples 
The OG and QB were provided by Ege Seramik Factory (Polat Holding Inc., Izmir, Turkey) and by Ünar Ltd. Company, respectively. The chemical analysis, the experimental compositions, and the calculated Seger formulation of the OG were respectively given in Tables 1,2 and 3 . The particle size of the OG was $-45 \mu \mathrm{m}$ and its specific gravity was $1.8 \mathrm{~g} / \mathrm{cm}^{3}(1800 \mathrm{~L} / \mathrm{g})$. The viscosity value of the OG (standard) at the factory was desired to be 24-25 s. QB was added to the standard OG at the weight ratios of $0.25,0.5,1.5,2,2.5,3.5,5$, and 10 (wt. \%) and mixed homogeneously with a magnetic stirrer (Chiltern) for an hour. The biscuit wall tiles previously cut in $5 \mathrm{~cm} \times 5 \mathrm{~cm} \times 0.5 \mathrm{~cm}$ dimensions were dried in an oven (Heraus) for two hours at $150{ }^{\circ} \mathrm{C}$ and were cooled down to room temperature. Subsequently, the glaze mixture prepared was applied onto the surfaces of the tile samples by dipping method. After cleaning off the excessive glaze slip spread on the underneath and the sides of the tile samples, they were left to dry at room temperature for 24 hours and again dried in the same drying oven at $150{ }^{\circ} \mathrm{C}$. Afterwards, they were heated to $1100{ }^{\circ} \mathrm{C}$ in a muffle furnace (Rohde). The heating and cooling rate of the furnace (Protherm PAF120/12 model) was $15{ }^{\circ} \mathrm{C} / \mathrm{min}$ and the dwelling time was 2 hours.

\subsection{Methods of physical and chemical tests}

Viscosity, thixotropy and $\mathrm{pH}$ tests were conducted on $\mathrm{OG}$ and $\mathrm{OG}+\mathrm{QB}$ glaze suspensions. Furthermore, the physical tests such as variation in colouring parameters, impact and crazing resistance, resistance to acids and alkalis, water absorption, firing strength, and surface hardness were carried out on $\mathrm{OG}$ and $\mathrm{OG}+\mathrm{QB}$ glazed tiles.

Table 1. Chemical analysis of OG (wt. \%).

\begin{tabular}{|l|l|l|l|l|l|l|l|l|}
\hline & $\mathrm{CaO}$ & $\mathrm{MgO}$ & $\mathrm{Na}_{2} \mathrm{O}$ & $\mathrm{K}_{2} \mathrm{O}$ & $\mathrm{ZnO}$ & $\mathrm{Al}_{2} \mathrm{O}_{3}$ & $\mathrm{SiO}_{2}$ & $\mathrm{ZrO}_{2}$ \\
\hline$\%$ & 8.37 & 2.38 & 8.05 & 4.65 & 11.25 & 7.01 & 50.1 & 8.19 \\
\hline
\end{tabular}

Table 2. Experimental OG compositions.

\begin{tabular}{|l|l|}
\hline Composition (\%) & Denotation \\
\hline $100 \mathrm{OG}$ & $0 \mathrm{QB}$ \\
\hline $99.75 \mathrm{OG}+0,25 \mathrm{QB}$ & $0.25 \mathrm{QB}$ \\
\hline $99.5 \mathrm{OG}+0.5 \mathrm{QB}$ & $0.5 \mathrm{QB}$ \\
\hline $99 \mathrm{OG}+1 \mathrm{QB}$ & $1 \mathrm{QB}$ \\
\hline $98.5 \mathrm{OG}+1.5 \mathrm{QB}$ & $1.5 \mathrm{QB}$ \\
\hline $98 \mathrm{OG}+2 \mathrm{QB}$ & $2 \mathrm{QB}$ \\
\hline $97.5 \mathrm{OG}+2.5 \mathrm{QB}$ & $2.5 \mathrm{QB}$ \\
\hline $96.5 \mathrm{OG}+3.5 \mathrm{QB}$ & $3.5 \mathrm{QB}$ \\
\hline $95 \mathrm{OG}+5 \mathrm{QB}$ & $5 \mathrm{QB}$ \\
\hline $90 \mathrm{OG}+10 \mathrm{QB}$ & $10 \mathrm{QB}$ \\
\hline
\end{tabular}

Table 3. Seger formulation of OG.

\begin{tabular}{lll}
$0.270 \mathrm{CaO}$ & $0.130 \mathrm{Al}_{2} \mathrm{O}_{3}$ & $1.606 \mathrm{SiO}_{2}$ \\
$0.115 \mathrm{MgO}$ & $0.135 \mathrm{ZrO}_{2}$ \\
$0.250 \mathrm{Na}_{2} \mathrm{O}$ & \\
$0.10 \mathrm{~K}_{2} \mathrm{O}$ & \\
$0.270 \mathrm{ZnO}$ & \\
\hline
\end{tabular}

\subsubsection{Viscosity and thixotropy tests}

Viscosity and thixotropy were determined by using DIN 53211 Flow Cup with $4 \mathrm{~mm}$ nozzle according to the related standard [9].

\subsection{2. $\mathrm{pH}$ values}

All the glaze suspensions were subjected to $\mathrm{pH}$ tests using a pH-meter ( $\mathrm{pH} 7110$ benchtop meter).

\subsubsection{Colour variation}

The colorimetric analyses of the whole samples were carried out at Ege Seramik Inc. using Erichsen Spectromaster 565-D according to TS EN ISO 10545-16 [10]. The results were given as trichromatic chromaticity coordinates. Whiteness or opacity is given with "L" values, variation between green and red colours with "a" values, and finally variation between blue and yellow colours with "b" values [11-12].

\subsubsection{Crazing resistance}

Crazing resistance of $\mathrm{OG}$ and all QB glazes were determined according to TS EN ISO 10545-11 [13].

\subsubsection{Impact resistance}

Impact resistance test was applied to all the samples according to TS EN ISO 10545-5 [14].

\subsubsection{Resistance to acid and alkalis}

The resistance to acid and alkalis were determined according to TS EN ISO 10545-13 [15].

\subsubsection{Water absorption}

The water absorption of $\mathrm{OG}$ and QB tiles were determined according to TS EN ISO 10545-3 [16].

\subsubsection{Fired strength}

This test was applied to all the glazed tiles according to TS EN ISO 10545-4 [17].

\subsubsection{Surface hardness}

All the glazed bodies were subjected to surface hardness test according to TS EN 101 [18]. 


\section{Results and Discussion}

\subsection{Viscosity tests}

Figure 1 shows the variation in flow time (viscosity) with QB concentration. The flow time initially decreased with increasing QB content from 10.9 down to 10.1 approximately between 0.25 and 2.5 wt. \% QB. Afterwards, the flow time increased progressively with increasing QB content about up to $11.2 \mathrm{~s}$ at $10 \mathrm{wt} . \%$ QB. When the viscosity of the standard OG (24-25 s)

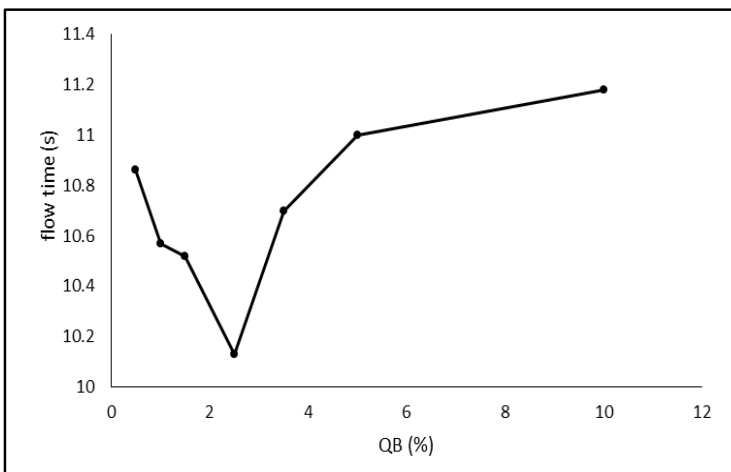

Figure 1. Variation in flow time (viscosity) with respect to QB content.

was taken into consideration, one can say that QB addition had a strong decreasing effect on viscosity. In other words, decreasing viscosity can be translated as an increase in fluidity of the OG slurry containing QB.

\subsection{Thixotropy tests}

Figure 2 indicates the variation of thixotropy values of the glaze suspensions with increasing QB content. The thixotropy values of experimental $\mathrm{OG}$ decreased approximately from $13.8 \%$ at 0.25 wt. $\%$ QB down to a minimum of $11 \%$ at 5 wt. \% QB content. Afterwards, the thixotropy values slightly increased about to $11.5 \%$ at 10 wt. \% QB content. Thus, it was clearly seen that QB had a great effect on thixotropy as in the case of viscosity. QB additions decreased the standard thixotropy value of $27-28 \%$ down to $11 \%$ at $5 \mathrm{wt}$. $\%$ QB addition, which corresponded to $61 \%$ decrease in thixotropy. In other words, decreasing thixotropy values can be interpreted in such a way that QB additions help

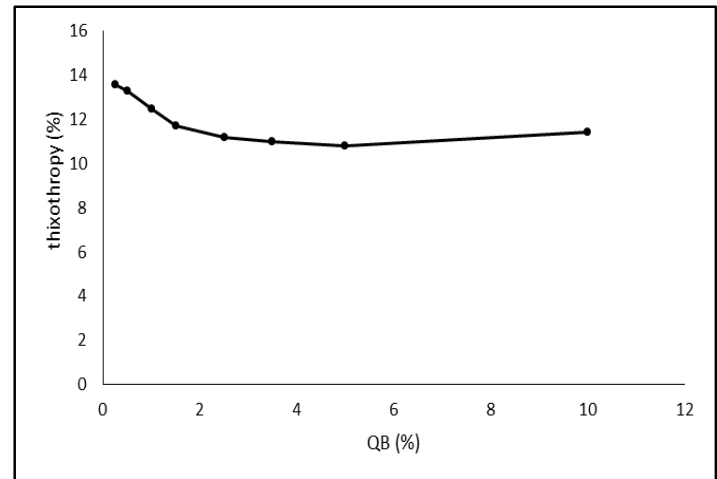

Figure 2. Variation in thixotropy with respect to QB content. the standard OG to keep its fluidity after a certain period of time.

Viscosity of glaze slurries is an important factor in their performance. The higher the viscosity, the thicker the application of glaze on ceramic ware [19]. However, a least amount of glaze should be deposited over the entire piece in order to use glaze slurry economically. An opaque glaze will require a thicker coating of glaze to provide a consistent colour and finish over the whole piece [20]. On the other hand, a thixotropic glaze slurry that stiffens quickly when left undisturbed can be very disturbing leading to need of a lot of agitation during storage. In the present study, QB additions decreased the viscosity and thixotropy values of standard OG acting as an effective deflocculant without compromising from the quality and properties of standard $O G$ as it was exhibited from the standard test results which were given in the following sections below.

\section{3. pH tests}

Figure 3 depicts the variation of $\mathrm{pH}$ values with increasing concentration of $\mathrm{QB}$. The $\mathrm{pH}$ values varied between 7 and 8 . When the $\mathrm{pH}$ value of standard OG, which is between 7.2 and 8.2, was taken into account, it was seen that QB had no significant effect on the $\mathrm{pH}$ of OG slurry (Figure 3).

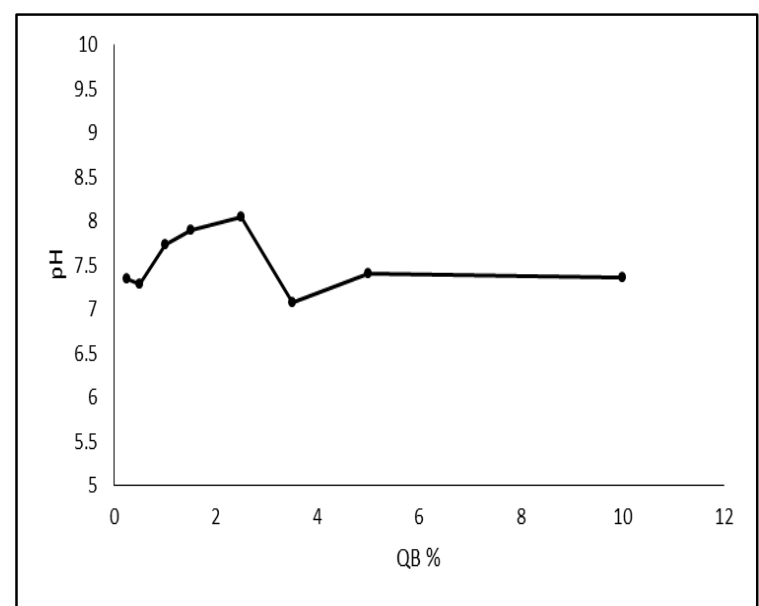

Figure 3. Variation in $\mathrm{pH}$ with respect to QB content

\subsection{Colour variation}

Table 4 gives the variation in the colour of the glazed tiles containing various ratios of $\mathrm{QB}$. There was no significant variation in the colouring parameters of the experimental glazes. However, the "L" values of the standard $O G$ was much lower than those of the experimental glazes, which demonstrated that QB additions clearly increased the opaqueness (whiteness) of the standard OG (Table 4, Figure 4). 
Table 4. Variation of colour with respect to QB content.

\begin{tabular}{|l|l|l|l|}
\hline Sample & $\mathrm{L}$ & $\mathrm{a}$ & $\mathrm{b}$ \\
\hline Standard OG & 86.58 & 0.23 & 13.68 \\
\hline QB 0,25 & 95.17 & 2.17 & 4.94 \\
\hline QB 0,5 & 95.68 & 1.83 & 3.95 \\
\hline QB 1 & 95.76 & 1.99 & 3.76 \\
\hline QB 1,5 & 95.62 & 1.96 & 3.65 \\
\hline QB 2 & 95.6 & 1.96 & 3.65 \\
\hline QB 2,5 & 95.31 & 1.83 & 4.44 \\
\hline QB 3,5 & 95.14 & 1.69 & 3.94 \\
\hline QB 5 & 94.18 & 1.91 & 4.38 \\
\hline QB 10 & 94.88 & 1.38 & 3.86 \\
\hline
\end{tabular}

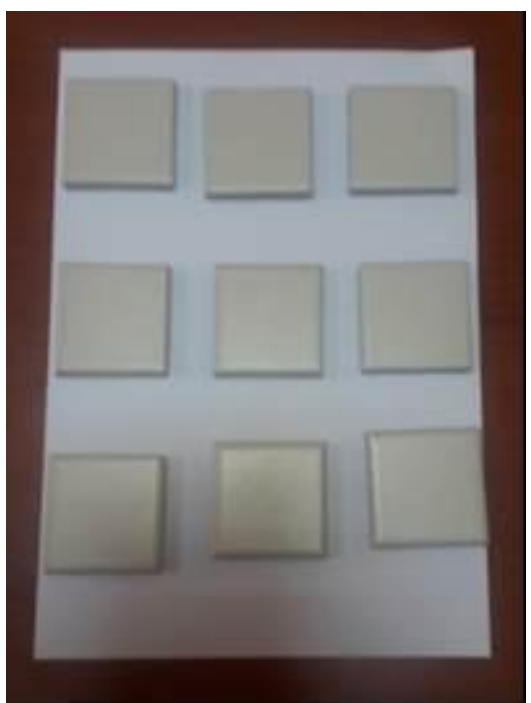

Figure 4. Glazed tiles subjected to colorimetric analyses.

\subsection{Crazing and impact resistance}

The results of crazing and impact resistance tests of the experimental OG revealed that no crazing was detected on the glazed surfaces of the tiles (Figure 5). The impact

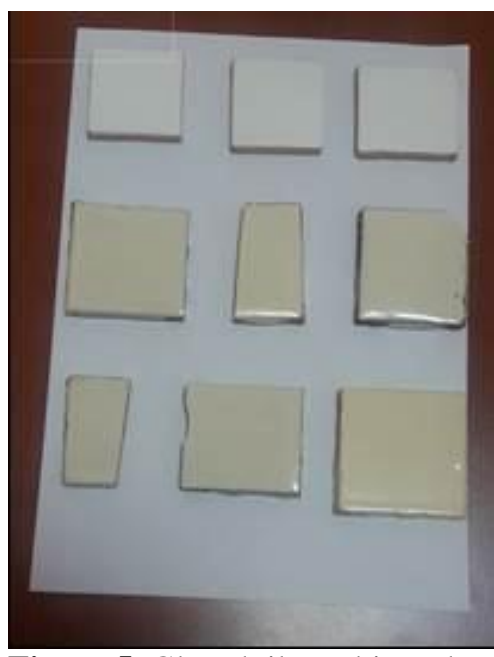

Figure 5. Glazed tiles subjected to crazing and impact resistance. tests were also conducted after the crazing resistance test on the same glazed tiles. None of the glazed surfaces was fractured after the impact tests (Figure 5).

\subsection{Resistance to acid and alkalis}

The resistance to acids and alkalis of the experimental OG can be seen in Figure 6. Firstly, resistance to alkalis was tested and no sign of abrasion on the glaze surface and no deterioration in the glaze colour were detected. Afterwards, resistance to acids test was carried out and again the glazed surfaces were smooth and no deterioration in colour was observed (Figure 6).

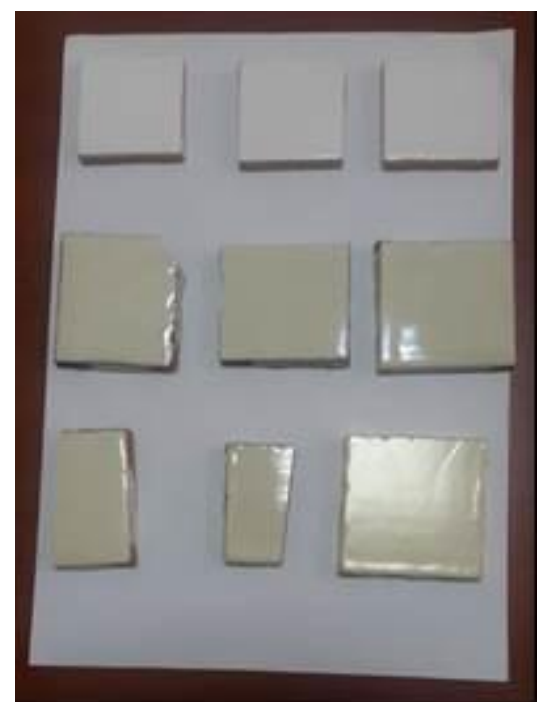

Figure 6. Glazed tiles subjected to resistance to acids and alkalis tests.

\subsection{Water absorption}

The water absorption values clearly decreased with increasing QB content (Figure 7) and reached to a minimum at $10 \mathrm{wt}$. \% QB content. When the maximum water absorption value of standard OG (18\% maximum) in the factory was compared with those of the experimental OG compositions, it was seen that QB clearly decreased the water absorption values throughout the experimental compositions.

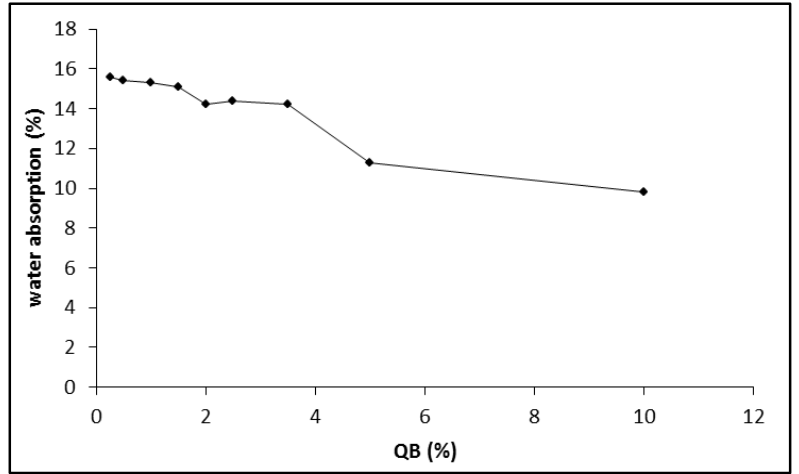

Figure 7. Variation in water absorption with respect to QB content. 


\subsection{Firing strength}

Figure 8 shows the variation of firing strength with QB concentration. Firing strength increased with an increase in QB content. Especially, at 5 and 10 wt. \% QB contents, the firing strength values were respectively around 80 and $105 \mathrm{~N} / \mathrm{mm}^{2}(\mathrm{~Pa})$ reaching a maximum value at 10 wt. \% QB. When the factory value of $40 \mathrm{~Pa}$ is taken into account, the firing strength increased by $100 \%$ and over.

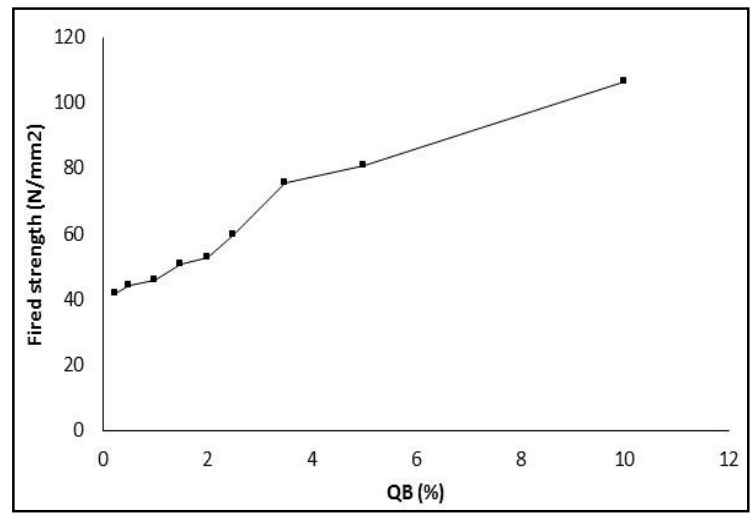

Figure 8. Variation in firing strength with respect to QB content.

\subsection{Surface hardness}

The surface hardness of the experimental OG compositions increased with increasing QB content (Figure 9). On the other hand, the surface hardness of the standard OG varies between 5.5 and 7 as reported by the factory. Thus, it is seen that the surface hardness values of the experimental OG were coherent with the standard values as seen from Figure 9.

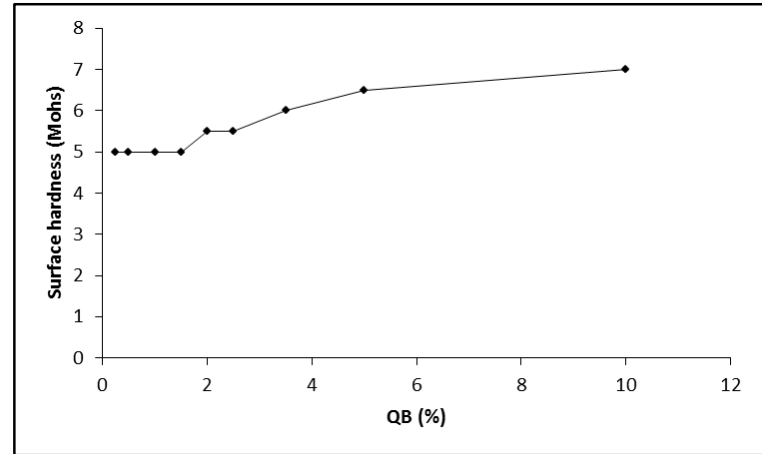

Figure 9. Variation in surface hardness with respect to QB content.

In the light of the discussion above and the experimental tests carried out in the present work, 5 wt. \% QB addition to the standard $\mathrm{OG}$ was found to be the optimum level. In this case, the viscosity will be around $11 \mathrm{~s}$ (the second highest) (Figure 1) and thixotropy 10.9 $\%$ (the lowest one) (Figure 2) among those of the rest of the experimental OG while the $\mathrm{pH}$ value will be around 7.25 being in conformity with that of standard OG. In other words decrease in viscosity and thixotropy will be respectively 56 and $61 \%$, which is desirable for OG slurry. At $5 \%$ QB addition, $\mathrm{L}$ value of the $\mathrm{OG}$ will be increased by around $10 \%$ (Table 4, Figure 4), which will definitely contribute to the opaqueness (whiteness) of the standard $\mathrm{OG}$ without compromising on the quality of the OG as far as the crazing resistance, impact resistance, and resistance to acid and alkalis are concerned (Figures 5 and 6). On the other hand, the water absorption value will be around $11 \%$ which means a $39 \%$ decrease in water absorption. Furthermore, at 5 wt. \% QB content, the firing strength will be $80 \mathrm{~N} / \mathrm{mm}^{2}(\mathrm{~Pa})$, which leads to about $100 \%$ increase in the firing strength which is desirable for this property. Similarly, the surface hardness will be around 6.25 which is in conformity with that of the standard OG.

\section{Conclusions}

The conclusions of this study were drawn as follows:

- QB additions had a strong decreasing effect on the viscosity of the $\mathrm{OG}$,

- QB additions decreased the standard thixotropy value of the OG,

- QB had no significant effect on the $\mathrm{pH}$ of the OG slurry,

- QB additions clearly increased the opaqueness (whiteness) of the OG,

- No crazing was detected on the glazed surfaces of the tiles due to QB additions,

- None of the glazed surfaces was fractured after the impact tests due to QB additions,

- The glaze surfaces demonstrated good resistance to acid and alkalis in spite of QB additions,

- QB incorporation clearly decreased water absorption throughout the experimental compositions,

- Firing strength increased with an increase in QB content

- Surface hardness increased with increasing QB content,

-5 wt. \% QB addition was found to be the optimum amount.

The results gathered demonstrated that QB was a good deflocculant and definitely increased strength, hardness and opacity of the glazes without compromising on the other qualities and properties of the standard OG.

\section{References}

1. Lakeside Pottery, Glazing - Mixing, Using, Application, Glazes Overview.

http:/www.lakesidepottery.com/HTML\%20Text/Tips/Mixing\%20 and\%20Using\%20Glazes.htm, 2018, (accessed 08.06.2018).

2. Singer, F. and Singer, S., Industrial Ceramics; Chapman and Hall: London, UK, 1984, 1455 pp.

3. İsrail, L İ., Köseoğlu, K., Cengizler, H., Effect of silver oxide on colour variation and gloss of opaque glazes, Transactions of the Indian Ceramic Society, 2014, 73, 22-30.

4. Pekkan, K., Karasu, B., Production of opaque frits with low $\mathrm{zro}_{2}$ 
and zno contents and their industrial uses for fast single-fired wall tile glazes, Journal of Materials Science, 2009, 44, 2533-2540.

5. Parmelee, C. W., Harman, C. G., Ceramic glazes, 3 rd Edition, Cahners Books: Boston, USA, 1973, 612 pp.

6. Romero, C., Bark Ecology, Ecology, INFO 34. http:// www.ecology.info/bark-ecology.htm, 2012, (accessed 08.06.2018).

7. Bechtold, T., Mahmud Ali, A., Mussak, R. A. M., Reuse of ash tree bark as natural dyes for textile dyeing: process conditions and process stability, COTE, 2007, 123, 271-279.

8. Mckay, G., Porter, J. F., Prasad, G. R., The removal of dye colours from aqueous solutions by adsorption on low-cost materials, Water, Air, and Soil Pollution, 1999, 114, 223-229.

9. International standard DIN 53211Din4 Flow Cup.

10. TS EN ISO 10545-16, Ceramic tiles - Part 16: Determination of small colour differences, Turkey, June 2012.

11. Hunter, R. S., Harold, R. W., The Measurement of Appearance, 2nd edition. John Wiley and Sons Inc.: New York, USA, 1987.

12. HunterLab, "Hunter L, a, b Color Scale", Insight on Color, vol. 8 , no. 9, downloaded from http://www.hunterlab.com/appnotes/an08_96a.pdf, 2008, (accessed 08.06.2018).
13. TS EN ISO 10545-5, Ceramic tiles Part 2, Determination of dimensions and surface quality, Turkey, April 2000.

14. TS EN ISO 10545-11, Ceramic tiles - Part 11, Determination of crazing resistance for glazed tiles, Turkey, December 1997

15. TS EN ISO 10545-13, Ceramic tiles Part 13, Determination of chemical resistance, Turkey, April 2000.

16. TS EN ISO 10545-3, Ceramic Tile Part 2, Determination of water Absorption, apparent porosity, apparent relative density and bulk density, Turkey, April 2000.

17. TS EN ISO 10545-4, Ceramic Tile Part 4, Determination of modulus of rupture and breaking strength, Turkey, April 2000.

18. TS EN 101, Ceramic Tiles- Determination of scratch hardness of surface according to mohs, Turkey, April 1995

19. Digtalfire.com, Reference library. https://digitalfire.com/4sight/glossary/glossary_viscosity.html, 2015, (accessed 08.06.2018).

20. Spectrum glazes, Adjusting Glaze Viscosity and Density. http://www.spectrumglazes.com/viscpg.html, 2018, (accessed 08.06.2018). 